\title{
The effect of two novel cholesterol-lowering agents, disodium ascorbyl phytostanol phosphate (DAPP) and nanostructured aluminosilicate (NSAS) on the expression and activity of P-glycoprotein within Caco- 2 cells
}

\author{
Kristina Sachs-Barrable ${ }^{1}$, Jerald W Darlington ${ }^{2}$ and Kishor M Wasan ${ }^{1,3^{*}}$
}

\begin{abstract}
Background: Many drugs are substrates for P-glycoprotein (P-gp) and interactions involving P-gp may be relevant to clinical practice. Co-administration with P-gp inhibitors or inducers changes the absorption profile as well as the risk for drug toxicity, therefore it is important to evaluate possible P-gp alterations. The purpose of this study was to investigate the effect of two novel cholesterol-lowering agents, disodium ascorbyl phytostanol phosphate (DAPP) and nanostructured aluminium silicate (NSAS), a protonated montmorillonite clay, on $m d r-1$ gene expression and its protein, P-glycoprotein (P-gp) within Caco-2 cells.

Methods: The effects of DAPP and NSAS on the regulation of $m d r-1$ gene, P-gp protein expression and activity within Caco-2 cells, were determined using cell viability and cytotoxicity tests, RT-PCR, Western Blot analysis and bi-directional transport studies.

Results: We observed a significant down-regulation of mdr-1 mRNA (e.g. $38.5 \pm 17 \%$ decrease vs. control at $5 \mu \mathrm{M}$ DAPP and $61.2 \pm 25 \%$ versus control at $10 \mu \mathrm{M}$ DAPP; $\left.n=6, P^{*}<0.05\right)$ within Caco-2 cells. Western Blot analysis of P-gp expression showed that changes in $m d r-1$ gene expression lead to correlating changes in P-gp protein expression. This down-regulation of P-glycoprotein also resulted in decreased activity of P-glycoprotein compared to untreated control. In contrast, when Caco-2 cells were treated with NSAS, no changes in $m d r-1$ gene expression, P-gp protein expression nor P-gp activity were observed.

Conclusions: DAPP but not NSAS decreases P-gp mediated drug efflux through decreased $m d r-1$ gene expression and consequently decreased P-gp protein expression. These findings have to be taken into consideration when DAPP is concurrently given with other drugs that are substrates for P-gp since drug-drug interactions harbour a safety issue and alter bioavailability profiles.

NSAS does not have any P-gp altering properties and therefore might not affect drug-drug interactions. We conclude from this study that NSAS might make a safer drug candidate compared to DAPP for lowering LDL-cholesterol.
\end{abstract}

\footnotetext{
* Correspondence: Kishor.Wasan@usask.ca

'Division of Pharmaceutics and Biopharmaceutics, Faculty of Pharmaceutical Sciences, The University of British Columbia, 2405 Wesbrook Mall, Vancouver V6T 1Z3, British Columbia, Canada

${ }^{3}$ Drug Discovery and Development Research Group, College of Pharmacy and Nutrition, University of Saskatchewan, Saskatoon, Saskatchewan, Canada Full list of author information is available at the end of the article
} 


\section{Introduction}

It has been estimated that by 2030 the number of deaths due to Cardiovascular disease (CVD) will climb to 23.3 million and CVD will remain the single leading cause of death [1]. The World Health Organization recommends increased government investment in prevention and early detection through national programs that are aimed to prevent and control non-communicable diseases like CVD. The application of new research findings towards new and better treatments, personalized medical care and interventions as well as the implementation of updated and improved guidelines are necessary for better outcomes for patients.

Substantial scientific evidence highlights elevated cholesterol levels as a risk factor for coronary artery disease. Despite much clinical success, statins are not well tolerated by all patients. Sufficient LDL-cholesterol lowering cannot be achieved by statin monotherapy in every patient [2-4] and reduction of cardiovascular events can only be reduced by $33 \%$ in the most responsive patients [5]. In about $2-10 \%$ of patients on statins the side effects are very severe and therefore the statin therapy has to be discontinued and replaced with alternative therapies [6]. An alternative approach to decreasing LDL-cholesterol is inhibiting the absorption of dietary cholesterol using plant sterols and plant stanols (phytosterols and phytostanols), either as as dietary supplements or as additives in food products including margarine, cereals, juices and yogurt [7]. The ability of plant sterols to reduce serum cholesterol levels has been known since the 1920s and was confirmed by studies in animals and humans in the 1950s [8-10].

Despite considerable research, the mechanism by which they reduce cholesterol is a topic of debate. Phytosterols are poorly absorbed in the intestines (between $0.4 \%$ and $3.5 \%$ ), and as with cholesterol, they are poorly water soluble [11].

One explanation is that phytosterols compete with cholesterol for being incorporated into mixed micelles which are made of dietary fat, bile acids and sterols. Cholesterol not incorporated into the micelle phase is unable to cross the unstirred water layer that lines the intestinal wall and cannot be taken up by the enterocytes for subsequent packaging into chylomicrons. Other studies are suggestive of alternate mechanisms contributing to their LDL-cholesterol lowering characteristics. Kaneko et al. have proposed that phytosterols might function as agonists for the liver X receptor (LXR). LXR is a nuclear receptor responsible for upregulating cholesterol efflux pathways throughout the body [12]. Additionally, suppression of de novo cholesterol synthesis has been shown in a rat model [13].

Phytosterols can be modified to increase their micellar incorporation capacity by esterification with fatty acids and many different modified phytosterols have been tested for activity. One such well characterized phytosterol is disodium ascorbyl phytostanol phosphate (DAPP), also known as FM-VP4 (Figure 1). It is a water-soluble derivative of sitostanol and campestanol linked by esterification with an ascorbyl-phosphate group $[14,15]$. In animal studies with rats, gerbils and mice FM-VP4 effectively reduces dietary cholesterol absorption [16,17]. This cholesterol lowering effect also leads to a reduction of atherosclerotic lesion formation in apo $\mathrm{E}$ knockout mice, a model that represents atherosclerosis [18]. FM-VP4 has also shown a decrease in body mass without any toxic effects [19]. This dose dependent reduction of mass in mice treated with FM-VP4 was not due to an increase in resting metabolic rate or decreased food or water intake, but through decreased absorption or increased excretion of lipids.

Potent cholesterol-lowering characteristics without any significant toxic effects was also shown in preclinical and clinical studies [15,16]. A clinical study in 30 men demonstrated that up to $800 \mathrm{mg} /$ day of DAPP is safe and well tolerated for at least 4 weeks. LDL-cholesterol was significantly reduced by $6.6 \%(\mathrm{p}=0.02)$ in the $400 \mathrm{mg}$ per day group [20].

Another compound of interest is nanostructured aluminosilicate (NSAS). NSAS is a protonated montmorillonite (bentonite) clay. Bentonites are naturally occurring compounds and recent studies have demonstrated cholesterol lowering effects and define them as a new class of

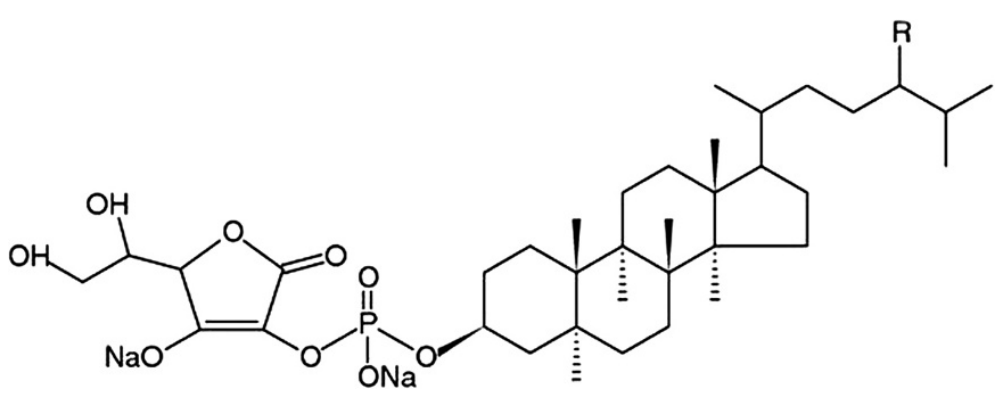

Figure 1 Chemical structure of DAPP. The two major components of DAPP are disodium ascorbyl campestanol phosphate and disodium ascorbyl sitostanol phosphate, each covalently linked to ascorbic acid by a phosphodiester bond [14,15]. 
cholesterol absorption inhibitors. NSAS can reduce the absorption of cholesterol by $39 \%$, similar to an identical dose of stigmasterol, by competing with cholesterol for absorption in the intestine after ingestion [21]. The first reported medical use of bentonite clay goes back to ancient Mesopotamia where it was applied externally as a mud bath and was touted for anti-inflammatory and antiseptic characteristics.

NSAS is composed of layers of aluminium octahedral sheets sandwiched between two silicon-oxygen tetrahedral layers (Figure 2). NSAS has a high surface area $\left(200-800 \mathrm{~m}^{2} / \mathrm{g}\right)$ and shows high water and organic material absorption characteristics either by adsorption onto its external surface or into its interlaminar space. It is negatively charged in contrast to positively charged bile acids and surface protons are incorporated to counterbalance platelet surface negative charge [22]. Additionally, NSAS appears relatively safe for oral administration and is minimally absorbed.
Oral administration of NSAS significantly inhibits cholesterol absorption in mice. Apo E knockout mice fed a diet high in cholesterol and fat were treated for 12 weeks with NSAS $(1.4 \% \mathrm{w} / \mathrm{w})$ or stigmastanol $(2 \% \mathrm{w} / \mathrm{w})$ and showed significant reductions in plasma cholesterol concentrations relative to control animals in both groups. No changes in food and water intake or body weight were observed. Atherosclerotic lesion formation at the aortic root was also reduced [23]. In vitro lipolysis studies adapted to stimulate intraluminal processing of triglycerides and cholesterol in the presence of NSAS showed an inhibition of cholesterol absorption either by direct binding to cholesterol or by other mechanisms like incorporation into micelles. Protonated NSAS adsorbs and sequesters cholesterol from the aqueous phase in the digestive tract resulting in precipitation and excretion with feces [24]. Potent inhibition of cholesterol absorption and minimal systemic exposure make NSAS a considerable candidate for treatment of hypercholesterolemia, either as adjunctive

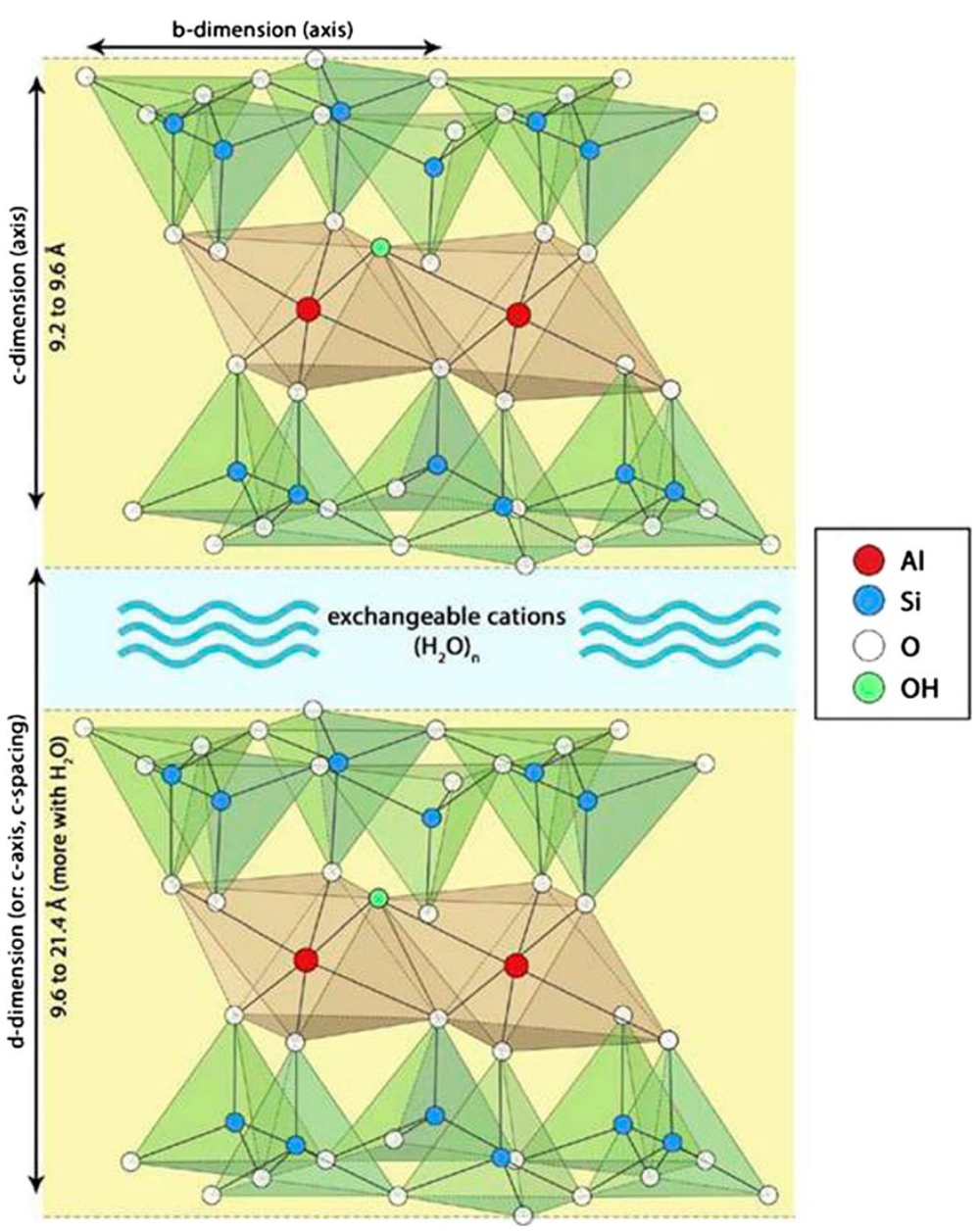

Figure 2 Structure of montmorillonite clay. Montmorillonite has a layer-lattice structure consisting of two sheets of tetrahedral siliconcrystals enclosing a sheet of octahedral aluminium crystals. Water and surface cations enter between adjacent silicon sheets causing the material to expand. 
therapy with statin or as monotherapy in patients unable to tolerate statins.

Most cardiovascular patients require multiple medications in addition to lipid lowering therapy, creating the possibility for drug interactions. Many of these drugs are substrates for P-glycoprotein (P-gp), which mitigates cellular exposure to various hydrophobic compounds thereby protecting cells from xenobiotics and other potential toxins. P-gp is expressed in numerous tissues including the small intestine, blood-brain barrier, hepatocytes, and kidney proximal tubule which affects intracellular and systemic drug concentrations; therefore, it is important to understand the behaviour of new drugs and therapies in regards to modification of P-gp.

P-gp belongs to the ATP-binding cassette (ABC) superfamily, which in humans, consists of several hundred transmembrane transport proteins which belong to 7 distinct subfamilies named ABCA - ABCG. They import and export a broad variety of substrates across cellular membranes including amino acids, lipids, drugs, and proteins. $\mathrm{ABC}$ genes are essential for many processes in the cell and mutations cause or contribute to several genetic disorders such as cystic fibrosis, neurological disease, retinal degeneration, Stargardt disease, cholesterol and bile transport defects, anemia, and abnormal drug responses). P-gp was the first identified human $\mathrm{ABC}$ transporter gene [25] and was first described in drug-resistant cells with a defined pattern of multidrug resistance [26]. P-gp relies on ATP as an energy source for drug efflux. Humans have two multidrug resistance (mdr) genes $m d r-1$ and $m d r-2$ (also called $m d r-3$ ), whereas rodents have three $m d r$ genes $m d r-1 A$ (also called $m d r-3$ ), $m d r-1 B$ (also called $m d r-1$ ) and $m d r-2$. Only $m d r-1$ in humans and $m d r-1 A \mathcal{E} B$ in rodents are involved in drug transport and drug-resistance [27,28]. Expression of P-gp in intestinal epithelial cells is responsible for efflux that limits cellular uptake into enterocytes and drug absorption. Drugs can be defined as P-gp inhibitors, P-gp enhancers or P-gp substrates. P-gp inhibitors impair P-gp mediated efflux while inducers enhance P-gp activity. A multitude of drugs, including several with a narrow therapeutic index, interact with $\mathrm{P}$-gp and drug-drug interactions must be considered given their impact on bioavailability and therapeutic outcome. Hence, the FDA now advises drug developers to characterize interactions between new drugs and P-gp, as stated in guidelines released in 2012 concerning drug-drug interactions. This just signifies the importance for evaluating P-gp interactions during novel drug development and to recommend clinical guidelines for clinicians when administering P-gp substrate drugs.

We studied the in vitro interactions between two novel cholesterol lowering agents, DAPP and NSAS, and the $\mathrm{P}$-gp transporter protein using Caco-2 cells.

\section{Materials and methods Materials}

NSAS was provided by AMCOL International Corporation (Chicago, USA). Triton X-100, Tween-80, HEPES, Protease inhibitor cocktail, $\mathrm{Na}$-deoxycholate, EDTA and $\mathrm{NaCl}$ were obtained from Sigma-Aldrich (St. Louis, MO, USA). All tissue culture reagents were from Invitrogen/Life Technologies (Grand Island, NY, USA). T-75 flasks, tissue culture treated plates and Transwell $^{\odot}$ inserts were from Corning Incorporated (Corning, NY, USA). CytoTox $96^{\circ}$ Non-Radioactive Cytotoxicity Assay, MTS CellTiter $96^{\circ} \mathrm{AQ}$ ueous One Solution Cell Proliferation Assay and Pgp-Glo ${ }^{\mathrm{TM}}$ Assay were from Promega Corporation (Madison, WI, USA). BCA ${ }^{\mathrm{TM}}$ Protein Assay Kit was obtained from Pierce Biotechnology, Inc. (Rockford, IL, USA). NP-40 was purchased from Roche Applied Science and Trans-Blot ${ }^{\odot}$ Transfer medium (nitrocellulose membrane $0.45 \mu \mathrm{M}$ ) from Bio-Rad (Hercules, CA, USA).

\section{Methods \\ Cell culture}

Caco-2, human colon adenocarcinoma cells, were purchased from ATCC (Rockville, MD, USA) and passage numbers between 20 and 35 were used. Cells were cultured in Dulbecco's modified Eagle's medium (DMEM), supplemented with $10 \%$ fetal bovine solution (FBS), $292 \mu \mathrm{g} \mathrm{mL}^{-1}$ L-glutamine, $0.1 \mathrm{mM}$ non-essential amino acids, $100 \mathrm{U} / \mathrm{mL}$ penicillin and $100 \mu \mathrm{g} / \mathrm{mL}$ streptomycin containing $1.5 \mathrm{~g} / \mathrm{L} \mathrm{NaHCO}_{3}$ at $37^{\circ} \mathrm{C}$ in humidified air containing $5 \% \mathrm{CO}_{2}$. Stock cultures were grown in T-75 flasks. Once the cells reached a confluency of about $90 \%$, they were then split by using $0.25 \%$ trypsin containing $1.0 \mathrm{mM}$ EDTA. Cells were seeded in 96-well, 48-well, 12-well, or Transwell plates depending on the type of experiment. The medium was changed every other day.

\section{Cytotoxicity measurements}

To determine non-cytotoxic concentrations, the following markers of toxicity were employed: 1) cell plasma membrane integrity as determined by lactate dehydrogenase $(\mathrm{LDH})$ release and 2) mitochondrial respiration as measured by the reduction of a tetrazolium compound (MTS) to a soluble formazan product. Caco-2 cells were seeded onto 96 -well plates and were kept at $37^{\circ} \mathrm{C}$ in humidified air containing $5 \% \mathrm{CO}_{2}$ until the cells reached $90 \%$ confluency. On the day of the experiment, the culture medium was exchanged for treatment solutions of 0 to $1000 \mu \mathrm{g} / \mathrm{mL}$ NSAS or 0 to $500 \mu \mathrm{M}$ DAPP and $1 \%$ Triton $\mathrm{X}-100$ (as positive control for cytotoxicity) in Hanks' Balanced Salt Solution without phenol (HBSS) containing 10 mM HEPES, pH 7.4. LDH release (CytoTox96 ${ }^{\circ}$ Non-Radioactive Cytotoxicity Assay), MTS reduction (CellTiter $96^{\circ} \mathrm{AQ}_{\text {ueous }}$ One Solution Cell proliferation Assay) and bicinchoninic acid (BCA ${ }^{\mathrm{TM}}$ Protein Assay Kit) 
assays were then performed, and cell viability was calculated relative to the $100 \%$ control (MTS-Assay). Cytoxicity was calculated relative to $100 \%$ cytotoxicity obtained from the Triton X-100 group (LDH-Assay).

\section{Protein expression: western blotting}

Protein levels were qualitatively observed by Western blot techniques. Caco-2 cells were treated with culture medium (control) or culture medium containing noncytotoxic concentrations of NSAS or DAPP. Cells were washed three times with PBS and harvested with RIPA lysis buffer (50 mM HEPES, $150 \mathrm{mM} \mathrm{NaCl}$, 2 mM EDTA, $0.5 \%$ Na-deoxycholate, $1 \%$ NP-40) containing protease inhibitor cocktail (1:100 dilution). Protein content was determined by $\mathrm{BCA}$ protein assay and the cell membrane proteins $(20 \mu \mathrm{g} / \mathrm{lane})$ were separated by electrophoresis through a 10\% SDS-polyacrylamide gel and then electroblotted onto a nitrocellulose membrane. A pre-stained protein standard from Bio-Rad was used to identify the P-gp protein band at $170 \mathrm{kD}$ and actin at $42 \mathrm{kD}$. The membrane was incubated overnight at $4{ }^{\circ} \mathrm{C}$ in blocking buffer $(1 \times$ PBS, $2.5 \%$ nonfat dried milk, $0.1 \%$ Tween-20), and probed with a 1:300 dilution of primary antibody (C219 from Signet Pathology System Dedlam) to detect P-gp and a 1:1000 dilution of I-19 (Santa Cruz Biotechnology) to detect actin as an internal control. The membranes were washed 3 times with PBS and 1\% Tween-20 (PBS-T) and the membrane was incubated in a 1:5000 dilution of anti-mouse IgG rabbit horseradish peroxidase (HRP)-conjugated antibody (Jackson ImmunoResearch Laboratories) and a 1:3000 dilution of anti-goat IRP bovine HRP (Santa Cruz Biotechnology) for P-gp and Actin respectively. Three washing steps with PBS-T followed. Bands were visualized with ECL and quantified with Labworks software (UVP).

\section{RNA-isolation and RT-PCR}

Caco-2 cells were harvested and total RNA was isolated with TRIzol ${ }^{\circ}$ Reagent (Invitrogen) according to the manufactures instruction. RNA was reverse transcribed into cDNA. The concentration of cDNA reaction product was measured by using Oligreen-Assay (Molecular Probes). The primers were synthesized at the Oligonucleotide Synthesis Laboratory at UBC. Parameters and conditions for the tested primers were optimized. The following primers were used for the described studies. Mdr-1 (5'- GTCATT-GTG-GAG-AAA-GGA-AAT-CAT-G-3 and 5' - ATTCCA-AGG-GCT-AGA-AAC-AAT-AGT-G-3' and GAP DH (5' - TGA-AGG-TCG-GAG-TCA-ACG-GAT-3' and 5' - TCG-CTC-CTG-GAA-GAT-GGT-GAT-3'). A sample from each PCR product was subjected to electrophoresis on a $1.5 \%$ agarose gel (containing Ethidium bromide). A 100 bp ladder was used to identify the size of PCR products. The fluorescent bands were imaged under UV light (UV-Epi Chemi II) and quantified with UVP-labworks software.

\section{Transmembrane transport of rhodamine 123}

Caco-2 cells form monolayers and express P-gp on their apical membranes thereby differentiating into a highly functionalized epithelial barrier that is morphologically and biochemically similar to small intestine columnar epithelium. A good system to measure apical and basolateral transport across monolayers and to determine the permeability of a certain substance is a Transwell ${ }^{\circ}$ plate. Cells are grown on a semi-permeable membrane which is placed between two chambers. Donor and acceptor chambers are determined by experiment type. To model intestinal drug absorption, the substance is given into the apical side and the concentration in the basolateral side is measured. Secretory transport can be determined if the substance is added onto the basolateral side and the concentration in the apical chamber is measured. P-gp mediated transport is characterized by basolateral to apical transport greater than apical to basolateral transport.

Caco-2 cells were seeded in polycarbonate membrane Transwell ${ }^{\circ}$ plates. at a densitiy of $40.000 \mathrm{cells} / \mathrm{cm}^{2}$ and grown in a humidified chamber (at $37^{\circ} \mathrm{C}$, of $5 \% \mathrm{CO}_{2}$.) with media changes every 2 days. The growth media (Dulbecco's minimal essential medium-DMEM) contained $10 \%$ heat-activated fetal bovine serum, $292 \mu \mathrm{g} / \mathrm{ml}$ glutamine, $0.1 \mathrm{mM}$ non-essential amino acids, $100 \mathrm{U} / \mathrm{ml}$ penicillin and $100 \mathrm{mg} / \mathrm{ml}$ glutamine. For the treatment experiments, NSAS or DAPP in different concentrations was added to the media and either applied onto apical and/or the basolateral side of the Transwell plate.

Transepithelial electrical resistance (TEER) of the monolayers was measured to confirm monolayer integrity with a Millicell Electrical Resistance System (Milipore Corp., Bedford, MA). Caco-2 cells with TEER Values above $300 \Omega \cdot \mathrm{cm}^{2}$ were used for transport studies. Cells were washed 3 times with PBS before treatment solutions were loaded on the apical side. Plates were incubated and TEER values were measured before and after the treatment to ensure integrity of the monolayer and tight junctions.

Rhodamine 123 (Rh123) is a fluorescent dye and P-gp substrate and has been used as a probe to measure the functional activity of P-gp. It has a molar extinction coefficient of $85,200 \mathrm{M}^{-1} \mathrm{~cm}^{-1}$ at $511 \mathrm{~nm}$. Rh123 was added to either the apical or basolateral chamber, with transport buffer in the corresponding receiver chamber. In a time dependent manner, samples $(50 \mu \mathrm{l})$ were collected with media replacement from receiver chamber and transferred into a 96-well plate. Rh123 concentrations were measured with a Fluoroskan Ascent fluorometer $($ excitation $=485 \mathrm{~nm}$ and emission $=$ $538 \mathrm{~nm}$ ). 
The apparent permeability $\mathrm{P}_{\text {app }}$ can be determined by using the following equation:

$$
\mathrm{P}_{\mathrm{app}}=\frac{\mathrm{dQ}}{\mathrm{dt} \mathrm{C}_{n}} \cdot \frac{\mathrm{I}}{\mathrm{A}}
$$

A is the area of absorption (cell monolayer), dQ/dt is the cumulative amount of test compound appearing in the receiver compartment of the assay system versus time, and $\mathrm{C}_{\mathrm{o}}$ is the initial concentration of the test compound in the donor compartment.

\section{Statistical analysis}

All data sets were analyzed for statistical significance by parametric methods using SigmaStat version 3.5. When comparisons were made between two groups, unpaired two-tailed $t$ tests were used. All data are expressed as mean \pm standard deviation.

\section{Results}

\section{Measurement of toxicity of NSAS and DAPP in Caco-2} cells

Treatment with concentrations between 0 and $500 \mu \mathrm{g} / \mathrm{ml}$ NSAS and 0 and $250 \mu \mathrm{M}$ DAPP showed no significant difference in cell viability compared to untreated control as measured by MTS assay (Figures 3A and 4A). Results from the LDH assay showed no significant cytoxicity for concentrations between 0 and $300 \mu \mathrm{g} / \mathrm{mL}$ NSAS and 0 and $100 \mu \mathrm{M}$ DAPP compared to untreated control (Figures $3 \mathrm{~B}$ and $4 \mathrm{~B}$ ). These nontoxic concentrations were subsequently used to treat cells for cholesterol uptake, transporter protein expression, Rh123 accumulation and transport studies across the Caco-2 cell monolayer.

\section{P-gp protein expression}

No changes in protein expression for P-glycoprotein were measured when Caco- 2 cells were incubated for 24 hours with NSAS at $10 \mu \mathrm{g} / \mathrm{mL}, 100 \mu \mathrm{g} / \mathrm{mL}$, and $500 \mu \mathrm{g} / \mathrm{mL}$ (Figure 5). However when Caco-2 cells were treated for the same length of time with DAPP a significant change was observed (Figure 6). Incubation with DAPP $10 \mu \mathrm{M}$ leads to a lesser expression of P-gp $(41 \pm 6 \%$ versus untreated control cells). We performed PCR reactions for those tested time points. A significant decrease in $m d r-1$ gene expression was observed when cells were treated with DAPP. All data obtained for mdr-1 gene expression were normalized for GAPDH gene concentration (Figures 5C and 6C).

In summary, down-regulation of $m d r-1$ gene expression was shown, complementing the results for decreased P-gp protein expression $(38.5 \pm 17 \%$ for treatment with $5 \mu \mathrm{M}$ DAPP and $61.2 \pm 25 \%$ for treatment with $10 \mu \mathrm{M}$ DAPP versus untreated control cells). Figure 6 shows the correlation from a decreased gene expression into decreased protein expression even after one week of treatment. The largest effect was seen for a concentration of $10 \mu \mathrm{M}$ of DAPP.

\section{Transmembrane transport of rhodamine 123}

Experiments were performed to measure the activity of P-gp in Caco-2 cells after treatment with DAPP.
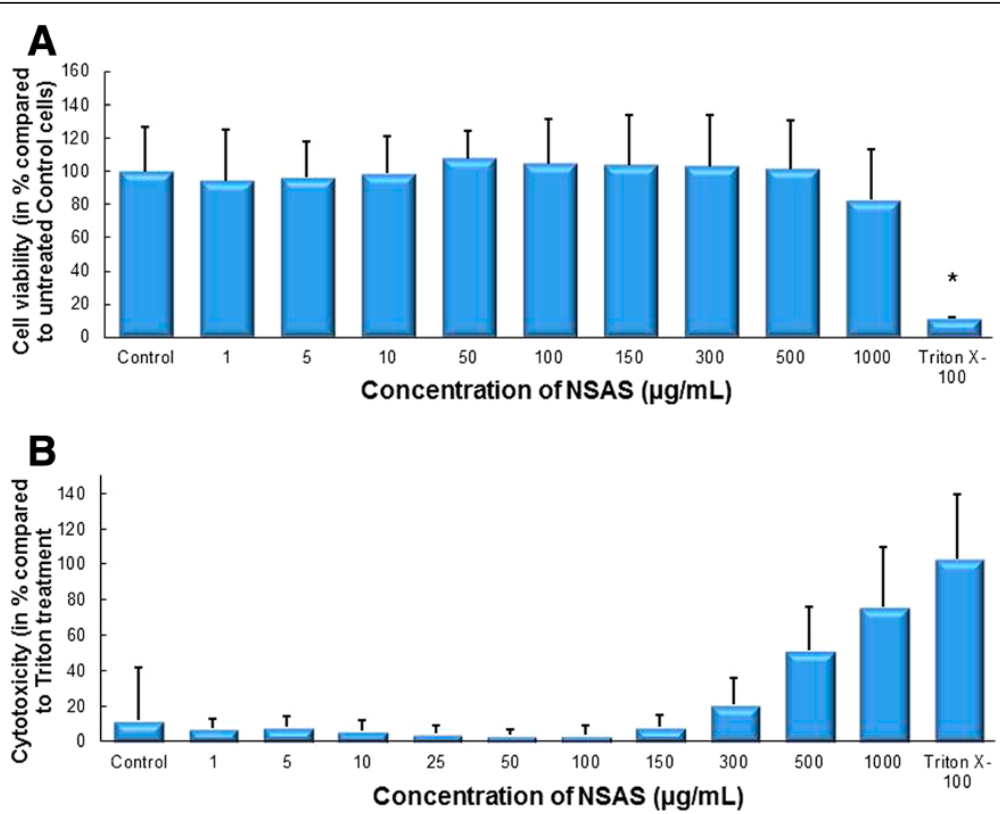

Figure 3 Cell viability and cytotoxicity after treatment with NSAS. Effect on Caco-2 cells. MTS-Assay (A) and LDH-Assay (B) after incubation with different concentrations of NSAS for 24 hours. Results are compared to untreated control cells (in A) and Triton X-100 (in B). Each bar represents the mean $\pm S D$. ${ }^{*} p<0.05 . N=3$. 

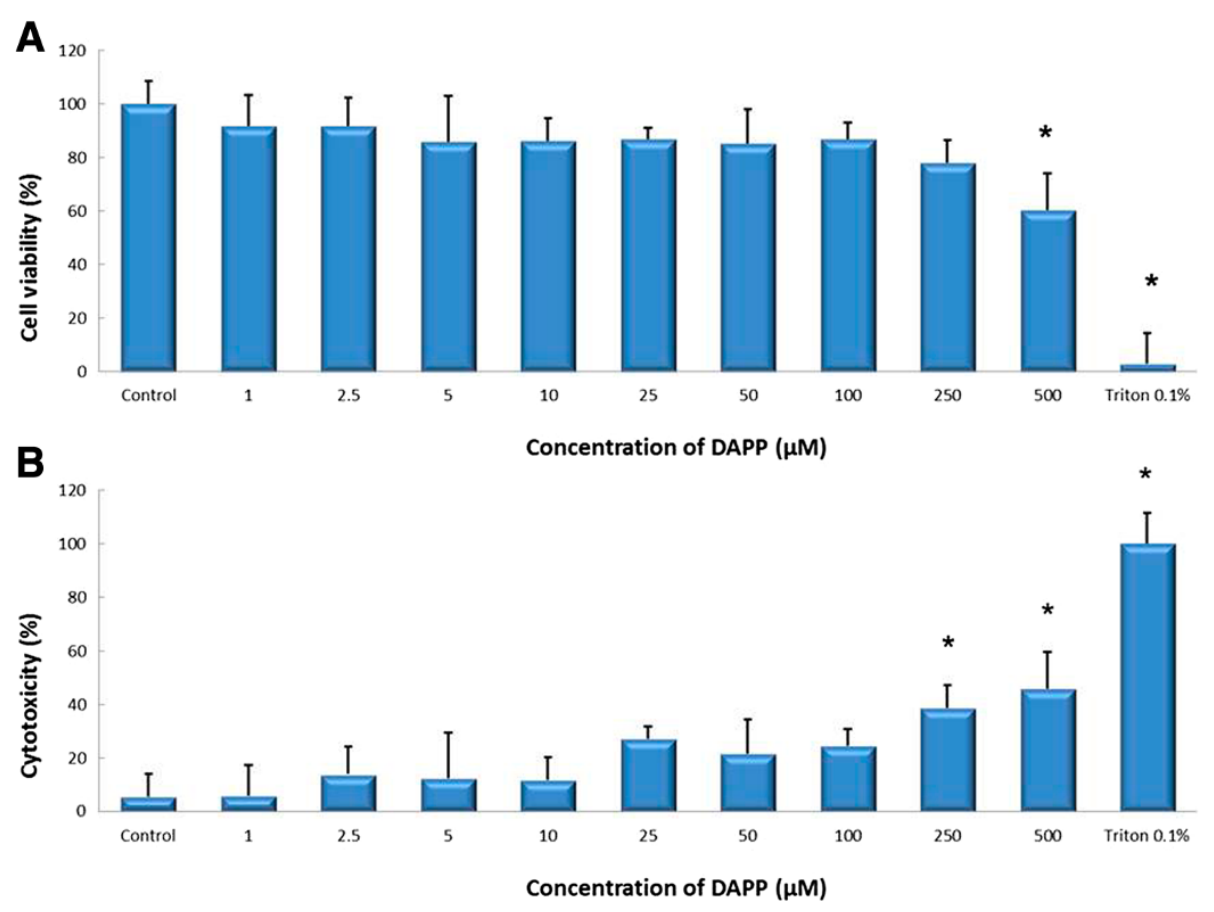

Figure 4 Cell viability and cytotoxicity after treatment with DAPP. Effect on Caco-2 cells. MTS-Assay (A) and LDH-Assay (B) after incubation with different concentrations of DAPP for 24 hours. Results are compared to untreated control cells (in A) and Triton X-100 (in B). Each bar represents the mean $\pm S D$. ${ }^{*} p<0.05 . N=4$.

We observed a significant down-regulation of $m d r-1$ m-RNA (e.g. $38.5 \pm 17 \%$ for treatment with $5 \mu \mathrm{M}$ DAPP and $61.2 \pm 25 \%$ for treatment with $10 \mu \mathrm{M}$ DAPP; $\mathrm{n}=6$, $\left.\mathrm{P}^{*}<0.05\right)$ within Caco-2 cells. Western Blot analysis of P-glycoprotein expression showed that changes in $m d r-1$ gene expression lead to correlating changes in P-gp protein expression. This down-regulation of P-glycoprotein also resulted in a decreased activity of P-glycoprotein compared to untreated control.

Treatment with 5 and $10 \mu \mathrm{M}$ DAPP resulted in a significant increase in Rh123 accumulation by two-fold relative to untreated control cells (Figure 7B). Accumulation of Rh123

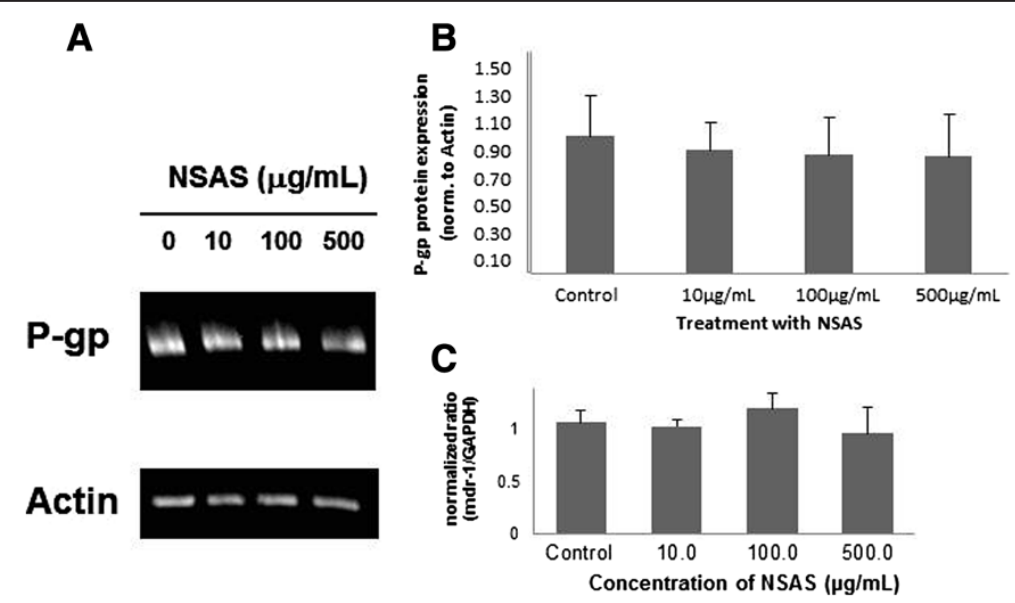

Figure 5 P-gp protein expression in Caco-2 cells after treatment with NSAS. Cells were exposed for 24 hours to media alone (control), $10 \mu \mathrm{g} / \mathrm{mL}, 100 \mu \mathrm{g} / \mathrm{mL}$ and $500 \mu \mathrm{g} / \mathrm{mL}$ NSAS compound A. (A) Representative Western Blot. (B) The data represent the mean \pm standard deviation of P-gp protein normalized by the protein expression of actin. There is no statistically significant difference between treatment groups and control. $\mathrm{N}=3$. (C) Expression profile of $m d r-1$ gene expression in Caco-2 cells. A sample from each PCR product was subjected to electrophoresis on a 1.5\% agarose gel and the fluorescent bands were quantified with UVP-Labworks software. Each value represents the mean \pm standard deviation of $N=3$. 


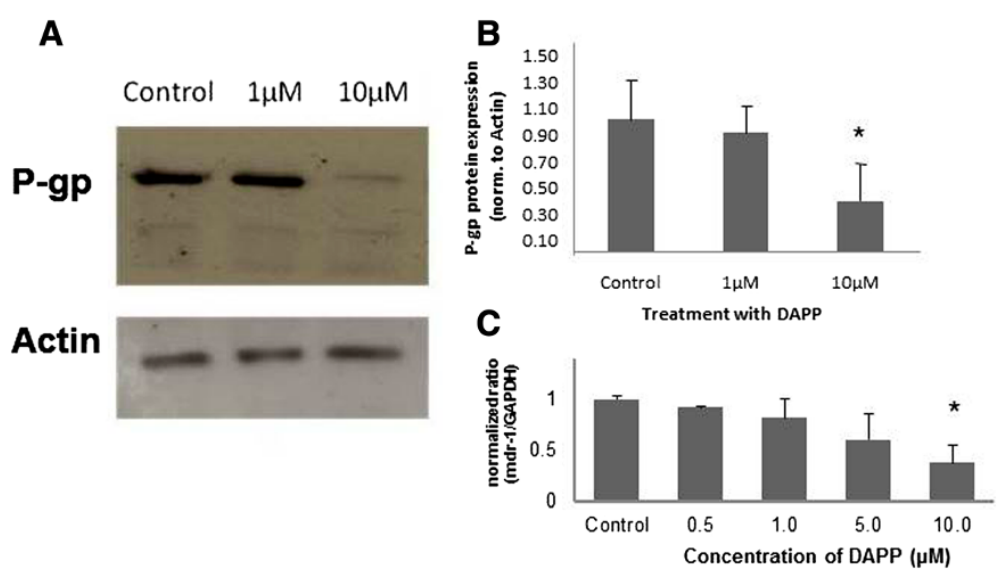

Figure 6 P-gp protein expression in Caco-2 cells after treatment with DAPP. Cells were exposed for 24 hours to media alone (control), $1 \mu \mathrm{M}, 10 \mu \mathrm{M}$ and $500 \mu \mathrm{M}$ DAPP. (A) Representative Western Blot. (B) The data represent the mean \pm standard deviation of P-gp protein normalized by the protein expression of actin. ${ }^{*} p<0.05$. $N=6$. (C) Expression profile of $m d r-1$ gene expression in Caco-2 cells. A sample from each PCR product was subjected to electrophoresis on a 1.5\% agarose gel and the fluorescent bands were quantified with UVP-Labworks software. Each value represents the mean \pm standard deviation of $\mathrm{N}=6 .{ }^{*} \mathrm{p}<0.05$.

in those Caco-2 cells is similar to Rh123 accumulation in cells treated with the positive control for P-gp inhibition, verapamil.

These findings suggest that DAPP not only has cholesterol-lowering properties but also decreases P-pg mediated drug efflux and might reverse multi-drug resistance.

DAPP treatment lead to a statistically significant decrease in secretory flux compared with untreated control cells (Figure 8), while TEER values stayed unchanged.

Bentonite on the other hand had shown cholesterol lowering characteristics without influencing transporter proteins. Also, no changes for Rh123 accumulation were observed (Figure 7A) when compared to untreated control cells.
In Summary DAPP has an influence on the expression of $m d r-1$; a decrease of the mRNA level lead to a decrease in P-glycoprotein expression. A corresponding decreased P-gp activity was also observed. None of those changes in $m d r-1$ gene expression, P-gp protein expression and activity were seen with NSAS.

\section{Conclusions}

Since the introduction of statins in the 1980s, they have become a golden standard of lipid-lowering therapy. They are prescribed for treatment of hypocholesterolemia and to reduce LDL-cholesterol and therefore reducing coronary artery disease-related morbidity and mortality. Over the past years statins have been proved to be safe and well-tolerated drugs. However there are more and

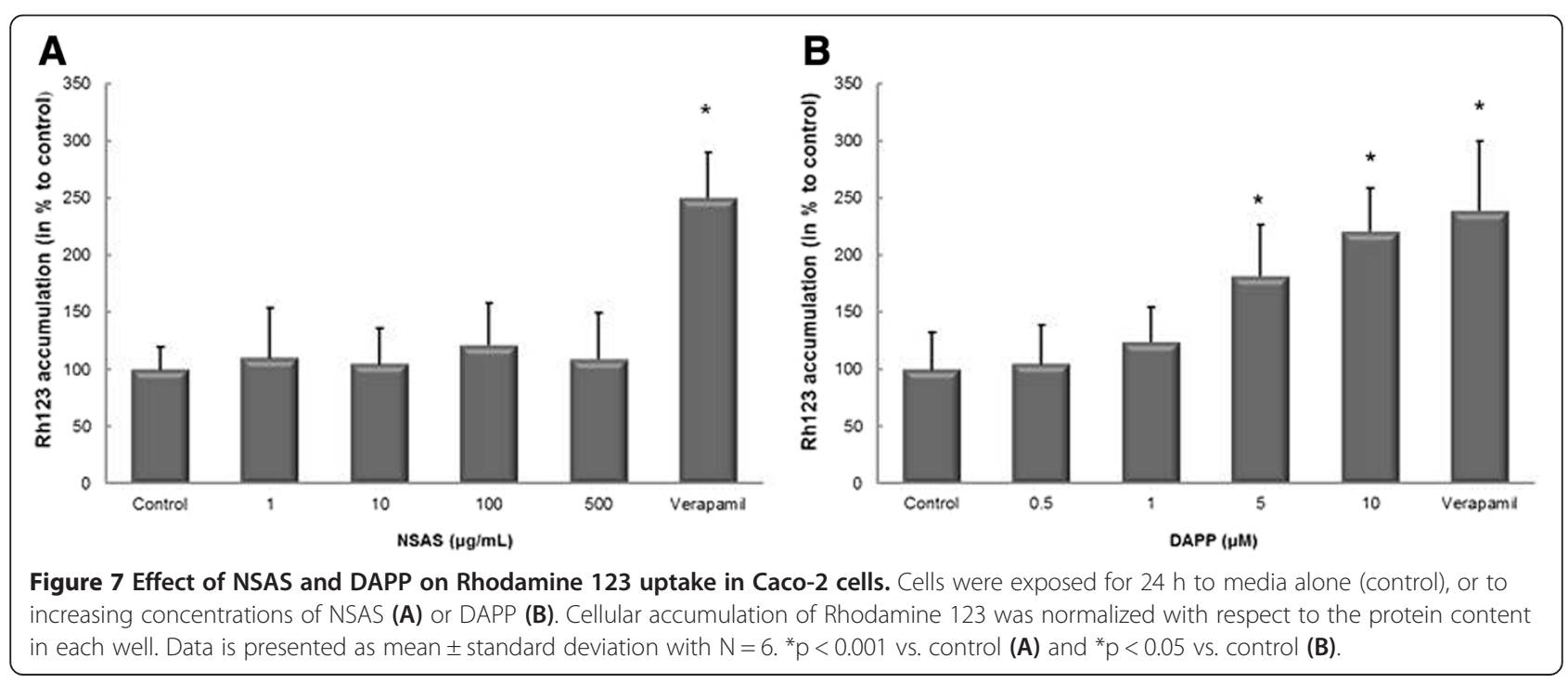




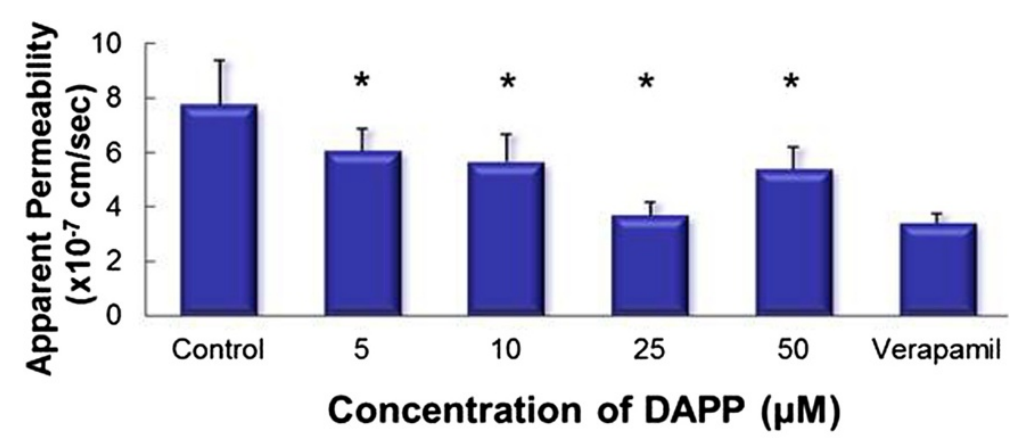

\begin{tabular}{|l|c|c|}
\hline \multicolumn{1}{|c|}{ DAPP } & $\begin{array}{c}\mathbf{P}_{\text {app }} \\
\left(* 10^{-7} \mathrm{~cm} / \mathrm{sec}\right)\end{array}$ & $\begin{array}{c}\text { SD } \\
\left(* 10^{-7} \mathrm{~cm} / \mathrm{sec}\right)\end{array}$ \\
\hline Control & 7.75 & 1.62 \\
$5 \mu \mathrm{M}$ & 6.08 & 0.81 \\
$10 \mu \mathrm{M}$ & 5.66 & 0.99 \\
$25 \mu \mathrm{M}$ & 3.68 & 0.48 \\
$50 \mu \mathrm{M}$ & 5.40 & 0.816 \\
$50 \mu \mathrm{M}$ Verapamil & 3.41 & 0.34 \\
\hline
\end{tabular}

Figure 8 Effect of pre-incubation with DAPP on P-gp transport of Rhodamine 123 across Caco- 2 cell monolayer (basolateral to apical transport) and apparent Permeability Papp. Data represent the average of $N=6 \pm S D$. ${ }^{*} p<0.025$. TEER values were measured before and after the treatment and at the end of the experiment. No changes in TEER values were seen which indicates the integrity of the monolayers. Treatment with DAPP lead to a statistically significant decrease in secretory flux compared with untreated control cells. Treatment with Verapamil represents a positive control for P-gp inhibition.

more reports on patients who either have an intolerance to statin treatment or experience minor to severe adverse reactions. The need for new and alternative therapies is more present and prominent. Studies of either new pharmacological agents or treatments in combination with established therapies are under way.

The study here investigates the effect on P-gp expression and activity of two substances, DAPP and NSAS, of the new class of cholesterol lowering agents.

This is of relevance for drug toxicity and efficacy since most patients take several medications simultaneously and many of the commonly prescribed drugs are substrates for P-gp. Drugs with narrow therapeutic indexes have shown large increases in concentration when co-administred with potent P-gp inhibitors or when the drug itself functions as P-gp inhibitor.

In previously published studies both agents (DAPP and NSAS) have shown a significant decrease in cholesterol absorption. This was tested in different models and no severe side effects were observed.

We found that unlike DAPP, NSAS did not change P-gp expression in our Caco-2 cell model. From that perspective NSAS may be a safer candidate for cholesterollowering treatment with regards to drug-drug interactions and adverse effects. Given our observation, DAPP has the potential to modulate P-gp mediated drug transport. Phytostanols and phytosterols have been widely used as additives to cereals, margarine, drinks and other food sources or are given as supplements to reduce serum cholesterol levels. Given the new findings of lowering P-gp protein expression and activity, this observation raises the possibility that when administered with other drugs, it might impact their uptake, bioavailability, and the therapeutic outcomes.

There are several limitations to this work and further studies are required to determine between these two agents and other $\mathrm{ABC}$ transporter proteins. Though P-gp is the most significant one, there are several other transporter proteins which may impact drug absorption such as multidrug resistance associated protein (MRP), breast cancer resistance protein (BCRP), organic anion transporter (OAT), organic anion transporting polypeptide (OATP), organic cation transporter (OCT) and oligopeptide transporter (PEPT). Additionally, these findings need to be confirmed in an animal model to evaluate clinical significance of our findings.

Data presented here further substantiate the need for addressing and investigating potential transporter protein interactions when developing new drug therapies.

\section{Competing interests}

Kishor Wasan and Kristina Sachs Barrable declare that they have no competing interests. However, Jerry Darlington is a Vice President of AMCOL Int. 


\section{Authors' contributions}

KW designed and implemented the experiments and wrote and edited the manuscript. KS-B completed the experiments and wrote and edited the manuscript. JD was involved in the design of the experiments and edited the manuscript. All authors read and approved the final manuscript.

\section{Acknowledgements}

The authors would like to thank Ankur Midha and Jacob Gordon from The University of British Columbia, Faculty of Pharmaceutical Sciences, for their critical feedback and discussions.

\section{Funding}

This work was supported by a University/Industry grant from the Canadian Institutes of Health Research (CIHR) and Amcol International Corporation.

\section{Author details}

'Division of Pharmaceutics and Biopharmaceutics, Faculty of Pharmaceutical Sciences, The University of British Columbia, 2405 Wesbrook Mall, Vancouver V6T 1Z3, British Columbia, Canada. ${ }^{2}$ AMCOL International Corporation, Chicago, USA. ${ }^{3}$ Drug Discovery and Development Research Group, College of Pharmacy and Nutrition, University of Saskatchewan, Saskatoon, Saskatchewan, Canada

Received: 27 May 2014 Accepted: 24 September 2014 Published: 1 October 2014

\section{References}

1. Mathers $C D$, Loncar D: Projections of global mortality and burden of disease from 2002 to 2030. PLoS Med 2006, 3:e442.

2. Bays H: Statin safety: an overview and assessment of the data-2005. Am J Cardiol 2006, 97:6C-26C.

3. Law M, Rudnicka AR: Statin safety: a systematic review. Am J Cardiol 2006, 97:52C-60C.

4. Nichols GA, Koro CE: Does statin therapy initiation increase the risk for myopathy? An observational study of 32,225 diabetic and nondiabetic patients. Clin Ther 2007, 29(8):1761-1770.

5. Libby $P$ : The forgotten majority: unfinished business in cardiovascular risk reduction. J Am Coll Cardiol 2005, 46:1225-1228.

6. Bruckert E, Hayem G, Dejager S, Yau C, Bégaud B: Mild to moderate muscular symptoms with high-dosage statin therapy in hyperlipidemic patients-the PRIMO study. Cardiovasc Drugs Ther 2005, 19:403-414.

7. Woodgate $\mathrm{D}$, Chan CHM, Conquer JA: Cholesterol-lowering ability of a phytostanol softgel supplement in adults with mild to moderate hypercholesterolemia. Lipids 2006, 41:127-132.

8. Pollak OJ: Reduction of blood cholesterol in man. Circulation 1953, 7:702-706.

9. Dempsey ME, Farquhar JW, Smith RE: The effect of beta sitosterol on the serum lipids of young men with arteriosclerotic heart disease. Circulation 1956, 14:77-82.

10. Pollak OJ: Effect of plant sterols on serum lipids and atherosclerosis. Pharmacol Ther 1985, 31:177-208,

11. Grundy SM: Stanol esters as a component of maximal dietary therapy in the National Cholesterol Education Program Adult Treatment Panel III report. Am J Cardiol 2005, 96:47D-50D.

12. Kaneko E, Matsuda M, Yamada Y, Tachibana Y, Shimomura I, Makishima M: Induction of intestinal ATP-binding cassette transporters by a phytosterol-derived liver X receptor agonist. J Biol Chem 2003, 278:36091-36098.

13. Batta AK, Xu G, Honda A, Miyazaki T, Salen G: Stigmasterol reduces plasma cholesterol levels and inhibits hepatic synthesis and intestinal absorption in the rat. Metabolism 2006, 55:292-299.

14. Ng AW, Lukic T, Pritchard PHWK: Development of novel water-soluble phytostanol analogs: disodium ascorbyl phytostanyl phosphates (FM-VP4): preclinical pharmacology, pharmacokinetics and toxicology. Cardiovasc Drug Rev 2003, 21(3):151-168.

15. Ng AW, Lukic T, Pritchard PH, Wasan KM: Development and characterization of liposomal disodium ascorbyl phytostanyl phosphates (FM-VP4). Drug Dev Ind Pharm 2004, 30:739-758.

16. Wasan KM, Najafi S, Peteherych KD, Pritchard PH: Effects of a novel hydrophilic phytostanol analog on plasma lipid concentrations in gerbils. J Pharm Sci 2001, 90:1795-1799.
17. Méndez-González J, Süren-Castillo S, Calpe-Berdiel L, Rotllan N, Vázquez-Carrera M, Escolà-Gil JC, Blanco-Vaca F: Disodium ascorbyl phytostanol phosphate (FM-VP4), a modified phytostanol, is a highly active hypocholesterolaemic agent that affects the enterohepatic circulation of both cholesterol and bile acids in mice. Br J Nutr 2010, 103:153-160.

18. Lukic T, Wasan KM, Zamfir D, Moghadasian MH, Pritchard PH: Disodium ascorbyl phytostanyl phosphate reduces plasma cholesterol concentrations and atherosclerotic lesion formation in apolipoprotein E-deficient mice. Metabolism 2003, 52:425-431.

19. Thornton SJ, Warburton C, Wasan KM, Kozlowski P: Treatment with a cholesterol absorption inhibitor (FM-VP4) reduces body mass and adipose accumulation in developing and pre-obese mice. Drug Dev Ind Pharm 2007, 33:1058-1069.

20. Vissers MN, Trip MD, Pritchard PH, Tam P, Lukic T, de Sain-van der Velden MG, de Barse M, Kastelein JJP: Efficacy and safety of disodium ascorbyl phytostano phosphates in men with moderate dyslipidemia. Eur J Clin Pharmacol 2008, 64:651-661.

21. Gershkovich P, Darlington J, Sivak O, Constantinides PP, Wasan KM: Inhibition of intestinal absorption of cholesterol by surface-modified nanostructured aluminosilicate compounds. J Pharm Sci 2009, 98:2390-2400.

22. Cai Y, Meng X, Cao Y, Lu H, Zhu S, Zhou L: Montmorillonite ameliorates hyperthyroidism of rats and mice attributed to its adsorptive effect. Eur J Pharmacol 2006, 551:156-161.

23. Sivak O, Darlington J, Gershkovich P, Constantinides PP, Wasan KM: Protonated nanostructured aluminosilicate (NSAS) reduces plasma cholesterol concentrations and atherosclerotic lesions in Apolipoprotein E deficient mice fed a high cholesterol and high fat diet. Lipids Health Dis 2009, 8:30.

24. Gershkovich P, Sivak O, Contreras-Whitney S, Darlington JW, Wasan KM: Assessment of cholesterol absorption inhibitors nanostructured aluminosilicate and cholestyramine using in vitro lipolysis model. J Pharm Sci 2012, 101:291-300.

25. Chen CJ, Chin JE, Ueda K, Clark DP, Pastan I, Gottesman MM, Roninson IB: Internal duplication and homology with bacterial transport proteins in the mdr-1 ( $P$-Glycoprotein) gene from multidrug-resistant human cells. Cell 1986, 47:381-389.

26. Juliano RL, Ling V: A surface glycoprotein modulating drug in chinese hamster ovary cell mutants permeability. Biochim Biophys Acta 1976, 455:152-162.

27. Roninson IB, Chin JE, Choi KG, Gros P, Housman DE, Fojo A, Shen DW, Gottesman MM, Pastan I: Isolation of human mdr DNA sequences amplified in multidrug-resistant KB carcinoma cells. Proc Natl Acad Sci U S A 1986, 83:4538-4542.

28. Fardel $\mathrm{O}$, Lecureur $\mathrm{V}$, Guillouzo $\mathrm{A}$ : The P-glycoprotein multidrug transporter Gen Pharmacol 1996, 27:1283-1291.

doi:10.1186/1476-511X-13-153

Cite this article as: Sachs-Barrable et al:: The effect of two novel cholesterol-lowering agents, disodium ascorbyl phytostanol phosphate (DAPP) and nanostructured aluminosilicate (NSAS) on the expression and activity of P-glycoprotein within Caco-2 cells. Lipids in Health and Disease 2014 13:153.

\section{Submit your next manuscript to BioMed Central and take full advantage of:}

- Convenient online submission

- Thorough peer review

- No space constraints or color figure charges

- Immediate publication on acceptance

- Inclusion in PubMed, CAS, Scopus and Google Scholar

- Research which is freely available for redistribution 